\title{
Effect of nipple shield use on milk removal: a mechanistic study
}

\author{
Viviane Silva Coentro ${ }^{1}$, Sharon Lisa Perrella ${ }^{1 *}$, Ching Tat Lai ${ }^{1}$, Alethea Rea ${ }^{2}$, Kevin Murray ${ }^{3}$ and \\ Donna Tracy Geddes'
}

\begin{abstract}
Background: Concerns about reduced milk transfer with nipple shield (NS) use are based on evidence from studies with methodological flaws. Milk removal during breastfeeding can be impacted by infant and maternal factors other than NS use. The aim of this study was to control electric breast pump vacuum strength, pattern and duration across multiple study sessions to determine if NS use reduces milk removal from the breast.

Methods: A within-subject study with two groups of breastfeeding mothers (infants $<6$ months) were recruited; Control Group (CG): no breastfeeding difficulties; Pain Group (PG) used NS for persistent nipple pain. Mothers completed three randomised 15 min pumping sessions using the Symphony vacuum curve (Medela AG); no NS, fitted NS, and a small NS. Sessions were considered valid where the applied vacuum was within $20 \mathrm{mmHg}$ of the set vacuum. Milk removal was considered as pumped milk volume, and also percentage of available milk removed (PAMR), which is calculated as the pumped volume divided by the estimated milk volume stored in the breast immediately prior to pumping.

Results: Of 62 sessions (all: $n=31$ paired sessions) a total of 11 paired sessions from both PG $(n=03)$ and CG $(n=08)$ were valid (subset) with and without a fitted NS. Only 2 small shield sessions were valid and so all small shield measurements were excluded. Both pumped volumes and PAMR were significantly lower with NS use for all data but not for subset data. (All: Volume and PAMR median: no NS: $76.5 \mathrm{~mL}, 69 \%$, Fitted NS: $32.1 \mathrm{~mL}, 41 \%$ respectively (volume $p=0.002$, PAMR $p=0.002$ ); Subset: Volume and PAMR median: no NS: 83.8 mL, 72\%; Fitted NS: 35.2 mL, 40\% (volume $p=0.111$ and PAMR $p=0.045$ ). The difference in PAMR, but not volume, was statistically significant when analysed by linear mixed modelling. A decrease of $10 \mathrm{mmHg}$ was associated with a $4.4 \%$ increase in PAMR $(p=0.017)$.
\end{abstract}

Conclusions: This experimental data suggests that nipple shield use may reduce milk removal. Close clinical monitoring of breastfeeding mothers using nipple shields is warranted.

Keywords: Nipple shield, Nipple pain, Pumping, Milk removal

\section{Background}

It is well known that early cessation of breastfeeding impacts both long and short-term health outcomes for the infant and mother $[1,2]$. Nipple pain is one of the most common causes of mothers stopping breastfeeding earlier

\footnotetext{
* Correspondence: sharon.perrella@uwa.edu.au

'School of Molecular Sciences, Faculty of Science, The University of Western Australia, M310, 35 Stirling Highway, Western Australia 6009 Crawley, Australia

Full list of author information is available at the end of the article
}

than planned [3-5]. The causes of nipple pain are varied and may be multifactorial, including suboptimal positioning and attachment, bacterial infection and vasospasm [68]. When nipple pain is unable to be resolved by conventional methods a nipple shield may be used [9]. A nipple shield is a thin flexible silicone aid that is placed over the nipple and areola prior to breastfeeding, providing a physical barrier with the aim of increasing maternal comfort while enabling continued breastfeeding. Many mothers

(c) The Author(s). 2020 Open Access This article is licensed under a Creative Commons Attribution 4.0 International License, which permits use, sharing, adaptation, distribution and reproduction in any medium or format, as long as you give appropriate credit to the original author(s) and the source, provide a link to the Creative Commons licence, and indicate if changes were made. The images or other third party material in this article are included in the article's Creative Commons licence, unless indicated otherwise in a credit line to the material. If material is not included in the article's Creative Commons licence and your intended use is not permitted by statutory regulation or exceeds the permitted use, you will need to obtain permission directly from the copyright holder. To view a copy of this licence, visit http://creativecommons.org/licenses/by/4.0/ The Creative Commons Public Domain Dedication waiver (http://creativecommons.org/publicdomain/zero/1.0/) applies to the data made available in this article, unless otherwise stated in a credit line to the data. 
continue using nipple shields as they are perceived to be helpful $[10,11]$. However, professional opinion remains divided on the use of nipple shields due to concerns about reduced milk transfer to the infant, altered infant sucking [12], and shorter breastfeeding duration [13, 14], although the latter is confounded by the fact that nipple shields are typically used by mothers experiencing breastfeeding problems [15].

Concerns about reduced milk transfer are based on studies performed more than three decades ago where both breastfeeding and breast pump use with a nipple shield resulted in lower milk transfer volumes than when breastfeeding or pumping without a nipple shield [12, 16]. Methodological issues such as small sample size, sampling prior to the establishment of a full milk supply, and absence of confirmation of adequate milk supply all call into question the validity of the reported results [10]. Further, in the pumping study, it was assumed that the breast was completely drained at the end of the pumping session, the duration of pumping prior to milk ejection was not accounted for, and achievement and maintenance of a set cycling pressure and pattern were not confirmed [16].

Assessment of milk removal with and without nipple shield use on can be confounded by variable infant sucking characteristics between study sessions, such as suck burst, pause and total feed durations, intraoral vacuum levels and infant alert state, satiety and age [17]. Also, it is not known if milk transfer volumes differ between women with and without nipple pain. We conducted a mechanistic study to exclude confounding infant factors, controlling and replicating breast pump vacuum strength, pattern and duration across study sessions to determine the effect of nipple shield use on milk removal during pumping in mothers with and without nipple pain.

\section{Methods \\ Participants}

Breastfeeding mothers of term healthy infants of ages 1 to 6 months were recruited through the Australian Breastfeeding Association, and international board certified lactation consultants based at the Breastfeeding Centre of Western Australia, King Edward Memorial Hospital or in the community between August 2016 and July 2018. Mothers were predominantly breastfeeding (i.e. feeding $\leq 1$ bottle of infant formula per day) and had previous experience of using a breast pump. We recruited two groups: a Pain Group (PG) where mothers were using a nipple shield to manage unexplained nipple pain, and a Control Group (CG) where the mothers had no breastfeeding difficulties.

PG inclusion criteria were: mothers with persistent nipple pain during breastfeeding despite professional lactation advice. CG inclusion criteria: mothers with no breastfeeding pain or difficulties. PG and CG exclusion criteria were: mothers with a diagnosed cause of nipple pain such as infection or nipple vasospasm, previous breast and/or nipple surgery and/or piercings, mothers < 18 years of age, mothers unable to read and speak English without assistance, birth $<37$ completed weeks gestation, mothers of infants with an oral anomaly, prior oral surgery and/or a diagnosed health condition. Mothers completed a demographic questionnaire at recruitment.

The study was granted approval by The University of Western Australia (RA/4/1/7863). Mothers provided written informed consent prior to participation.

\section{Study design}

A within-subject study was conducted in a laboratory at The University of Western Australia with mothers required to attend three study sessions. At each session one breast was pumped under one of three randomly assigned conditions: (1) with a fitted nipple shield i.e. nipple shield diameter $\geq 4 \mathrm{~mm}$ nipple diameter, (2) without a nipple shield, and (3) with a small nipple shield (nipple shield diameter $<4 \mathrm{~mm}$ nipple diameter, or $16 \mathrm{~mm}$ diameter nipple shield if nipple diameter $\leq$ $12 \mathrm{~mm}$ ). The small nipple shield was used to determine whether nipple shield sizing may explain differences in milk removal with nipple shield use. The same breast was pumped at each visit; the CG mothers' study breast was randomised, and PG mothers pumped the most painful breast as the indication for nipple shield use was nipple pain.

The pump used was a custom-made softwarecontrolled breast pump (Lactasearch, Medela AG, Baar, Switzerland) that applied the Symphony vacuum curve, with a vacuum range of 0 to $-250 \mathrm{mmHg}$ and frequency range of 120 cycles/min for the stimulation phase and 48 to 72 cycles/min for the expression phase. The applied vacuum was measured throughout the pumping sessions and data recorded using the software package DIAdem (version 11.1, National Instruments, Texas, USA, 2009). Mothers used a breast shield that was connected to a collection tube with expressed milk delivered to a bottle placed on a custom built continuous weighing device (ShowMilk, Medela AG, Switzerland; resolution $0.1 \mathrm{~g}$, accuracy $\pm 0.02 \%$ to a maximum $2 \mathrm{~kg}$ ).

Nipple diameters were measured using electronic callipers (CE Carbon Fiber Composites Digital Calliper, accuracy $\pm 0.2 \mathrm{~mm}$, Anhui, China) before pumping to determine the appropriate nipple shield size. Pre and post pumping milk samples $(<1.0 \mathrm{~mL})$ were collected in $5 \mathrm{~mL}$ plastic tubes (Techno Plas, St Marys SA, Australia). The cream content of the milk was measured using the Crematocrit method [18], and the degree of 
breast fullness was calculated using Crematocrit and $24 \mathrm{~h}$ milk profile results [19].

Central placement of the nipple shield and breast shield over the nipple were confirmed before commencing pumping with a stimulation pattern, with the vacuum setting immediately adjusted to the mother's maximum comfortable vacuum level. The expression pattern commenced when milk flow was visually detected, or at 2 min if milk flow had not occurred. The vacuum setting was again adjusted to the mother's highest comfortable vacuum level and applied for $15 \mathrm{~min}$. For each mother, the maximum comfortable vacuum level selected at the first pumping study session was set for subsequent sessions.

Mothers rated the severity of nipple pain experienced during each pumping session using the Visual Analogue Scale (VAS) [20, 21] and McGill Pain Questionnaire (MPQ) [22].

\section{Measurement of milk removal from the breast}

Maternal $24 \mathrm{~h}$ milk profile measurements were completed in mothers' homes within 14 days of the study sessions using electronic scales sensitive to $2 \mathrm{~g}$ (Medela BabyWeigh Scales, Medela AG, Baar, Switzerland). Milk production was determined by weighing the infant [23] pre and post breastfeeds and by weighing milk collection bottles pre and post any pumping sessions over a $24 \mathrm{~h}$ period. Milk samples $(<1.0 \mathrm{~mL})$ were collected before and after every breastfeed and pumping session and frozen for later analysis. All breastfeeding and pumping measurements were expressed in grams and considered equivalent to $\mathrm{mL}$ (1.03 $\mathrm{g} \mathrm{mL}^{-1}=1.0 \mathrm{~mL}$ of breast milk) [24].

As breast storage capacities differ between women and the volume of milk available in the breast varies over time, the volume of milk removed by breastfeeding or pumping is not an accurate indicator of the degree to which the breast was emptied $[18,25]$. Therefore, each mother's breast storage capacity, degree of breast fullness, and percentage of available milk removed (PAMR) were estimated as described by Kent et al. [26], thereby allowing more accurate comparisons between pumping sessions. For example, one mother may have a breast storage capacity of $100 \mathrm{~mL}$, and another mother a breast storage capacity of $200 \mathrm{~mL}$. If these two mothers pump from a full breast and each removes $50 \mathrm{~mL}$, the first mother will have removed $50 / 100 \mathrm{~mL}$ or $50 \%(50 \%$ PAMR) and the second mother $50 / 200 \mathrm{~mL}$ or $25 \%$ of the available milk (25\% PAMR). The PAMR reflects the degree of emptying and therefore effectiveness of milk removal more accurately than volume alone.

\section{Sample size determination}

The primary endpoint of this study is total milk volume removed during pumping with and without a nipple shield. Sample size determination for this project was completed using the data source of McClellan et al. [5] where raw data was sourced from 21 women reporting nipple pain and compared with 21 mothers without nipple pain with regard to $24 \mathrm{~h}$ milk production, milk transfer volumes, and estimated milk available in the breast $(\mathrm{mL})$. The sample size was calculated using a bootstrap approach where it considered two feeds and then added a nipple shield effect in one of the feeds. For the purpose of this sample size determination, it was assumed that nipple shield use decreases milk removal from the breast. All analyses were performed using $\mathrm{R}$, and a sample size of $30(n=30)$ was recommended to detect an average significant difference of $20 \pm 5 \mathrm{~mL}$ (power: 0.83 , alpha: 0.05 ) between sessions with and without nipple shield use.

\section{Statistical methods}

An interim review of the data showed that for 20 of 31 pumping sessions where a nipple shield was used, the applied vacuum did not reach the set vacuum. For these 20 sessions, we observed movement of the nipple shield and the applied vacuum was often more than $20 \mathrm{mmHg}$ weaker than the set vacuum. Valid data was difficult to obtain because the differences in vacuum could not be resolved technically. Therefore, analysis was carried out on all data and on the valid data (subset analysis). This subset was defined as mothers who had complete data for paired sessions (with and without fitted nipple shield use) where the applied maximum comfortable vacuum was within $20 \mathrm{mmHg}$ of the set vacuum across the sessions.

The data was analysed using linear mixed models with either PAMR or milk volume as the response variable and group (control or pain), nipple shield (none or fitted nipple shield), degree of breast fullness (milk volume models only) and applied vacuum (all models) as explanatory variables with a random effect for mother. Only two mothers had valid data for small nipple shield, fitted nipple shield and no nipple shield pumping sessions. Therefore data for the small nipple shield sessions were excluded as the data were insufficient to determine whether a use of a small nipple shield impacted milk removal. Model selection was carried out on all models in order to retain only significant variables in the final models.

Control and Pain groups $24 \mathrm{~h}$ milk productions, VAS and MPQ scores were compared using a Wilcoxin signed rank test. Control and Pain groups were compared using a Wilcoxin signed rank test for different conditions (with and without the nipple shield). Categorical data for demographic characteristics were compared using Fisher's exact test. Paired t-tests were used to compare of pumping characteristics with and without nipple shield use. 
Table 1 Maternal and pumping characteristics for Pain and Control groups

\begin{tabular}{|c|c|c|c|c|c|}
\hline \multirow[t]{2}{*}{ Maternal characteristics } & \multicolumn{3}{|l|}{ 'all data' } & \multicolumn{2}{|l|}{ 'subset data' } \\
\hline & PG $(n=09)$ & CG $(n=22)$ & $p$-value & $\begin{array}{l}\text { PG }(n=03) \\
\text { median only }\end{array}$ & CG $(n=08)$ \\
\hline Maternal age; years & $30(5)$ & $33(3)$ & 0.03 & 25.7 & $33.3(91.6)$ \\
\hline Primipara; n (\%) & $7(78)$ & $14(70)$ & 0.67 & $3(100)$ & $6(86)$ \\
\hline Birth gestation; weeks & $39(1)$ & $40(2)$ & 0.39 & 39 & $39(3)$ \\
\hline Birth mode vaginal; n (\%) & $5(56)$ & $14(64)$ & 0.70 & $2(67)$ & $4(57)$ \\
\hline Postpartum time; weeks & $11.0(4.4)$ & $15.1(11.1)$ & 0.04 & 11.0 & $15.7(11.3)$ \\
\hline 24 h milk production; mL & $768(178)$ & $739(305)$ & 0.89 & 654 & $622(98)$ \\
\hline Postpartum time of milk production; week & $6.7(2.4)$ & $13.4(6.6)$ & 0.04 & 6.6 & $12.6(6)$ \\
\hline \multicolumn{6}{|l|}{ Pumping characteristics } \\
\hline MCV, no nipple shield; mmHg & $-262(29)$ & $-232(59)$ & 0.14 & -240 & $-197(72)$ \\
\hline MCV, with nipple shield; mmHg & $-260(26)$ & $-236(59)$ & 0.20 & -238 & $-196(76)$ \\
\hline PAMR, no nipple shield; \% & $55(24)$ & $73(29)$ & 0.31 & 50 & $76(18)$ \\
\hline PAMR, with nipple shield; \% & $44(32)$ & $41(47)$ & 0.91 & 37 & $40(71)$ \\
\hline Volume, no nipple shield; mL & $59(60)$ & $82(60)$ & 0.56 & 57 & $102(52)$ \\
\hline Volume, with nipple shield; mL & $37(46)$ & $31(62)$ & 0.67 & 37 & $33(104)$ \\
\hline
\end{tabular}

Results are reported as median (IQR) for maternal age, birth gestational age, $24 \mathrm{~h}$ milk production (range), time of measuring milk production, maximum comfortable vacuum (MCV), percentage of available milk removed (PAMR) and volume with and without nipple shield (NS). Parity and birth mode are reported as number and percentage (\%)

Descriptive statistics are presented as medians (IQR) for numerical variables and frequencies and percentages for categorical variables. Model estimates are presented as estimate (standard error). The significance level was set at 0.05 and the analysis was carried out in $\mathrm{R}$ version 3.5.1.

\section{Results}

Maternal characteristics are shown in Table 1. Data were collected for up to three pumping sessions from 31 mothers in total (PG $n=09$, CG $n=22$ ), and results reported for 31 paired sessions of pumping without and with a fitted nipple shield. Valid data were obtained for 11 paired sessions to provide subset data for 11 mothers (PG $n=03$, CG $n=08$ ).

The $24 \mathrm{~h}$ milk production median volumes were similar between groups (Table 1). For the subset data median $24 \mathrm{~h}$ milk production were $654 \mathrm{~mL}$ for PG and $622 \mathrm{~mL}$ for CG.

For pumping sessions with a nipple shield, both volume and PAMR were lower for both all and the subset data (Table 2).

When considering all data, modelling showed that PAMR was lower with a nipple shield. When a fitted nipple shield was used the PAMR was 24.0 (6.8) percentage points lower than if no nipple shield was used ( $p=$ $0.002)$. For the subset data when a fitted nipple shield was used the PAMR was 28.2 (11.6) percentage points lower than if no nipple shield was used $(p=0.045)$. A decrease of $10 \mathrm{mmHg}$ in applied vacuum was associated with a 4.4 (1.4) percentage point increase in PAMR ( $p=$ 0.017). When considering the subset data only, PAMR was associated with nipple shield use and applied vacuum (Fig. 1).

Table 2 Degree of fullness, applied vacuums, milk volume and PAMR with and without nipple shield

\begin{tabular}{lccc}
\hline & \multicolumn{1}{c}{$\begin{array}{l}\text { No Nipple } \\
\text { Shield }\end{array}$} & Nipple Shield & $p$-value \\
\hline Degree of fullness & & \\
All data & $0.76(0.42)$ & $0.73(0.50)$ & 0.863 \\
Subset & $0.81(0.25)$ & $0.73(0.23)$ & 0.375 \\
Applied vacuum (mmHg) & & \\
All data & $-235(60)^{\mathrm{a}}$ & $-186(73)$ & 0.019 \\
Subset & $-218(66)^{\mathrm{a}}$ & $-220(59)$ & 0.770 \\
Volume (mL) & & & 0.002 \\
All data & $76.5(63.1)$ & $32.1(58.4)$ & 0.111 \\
Subset & $83.8(56.7)$ & $35.2(81.6)$ & \\
PAMR (\%) & & & 0.002 \\
All data & $69(33)^{\mathrm{a}}$ & $40.7(40)^{\mathrm{a}}$ & 0.045 \\
Subset & $72(19)^{\mathrm{a}}$ & $40.0(49)^{\mathrm{a}}$ & \\
\hline
\end{tabular}

ane record with missing data

Pre-pumping degree of fullness, applied pumping vacuums, milk volume and percentage of available milk removed (PAMR) with and without nipple shield presented reported as raw data as median (IQR) for all data $(n=31)$ and subset data $(n=11)$ 


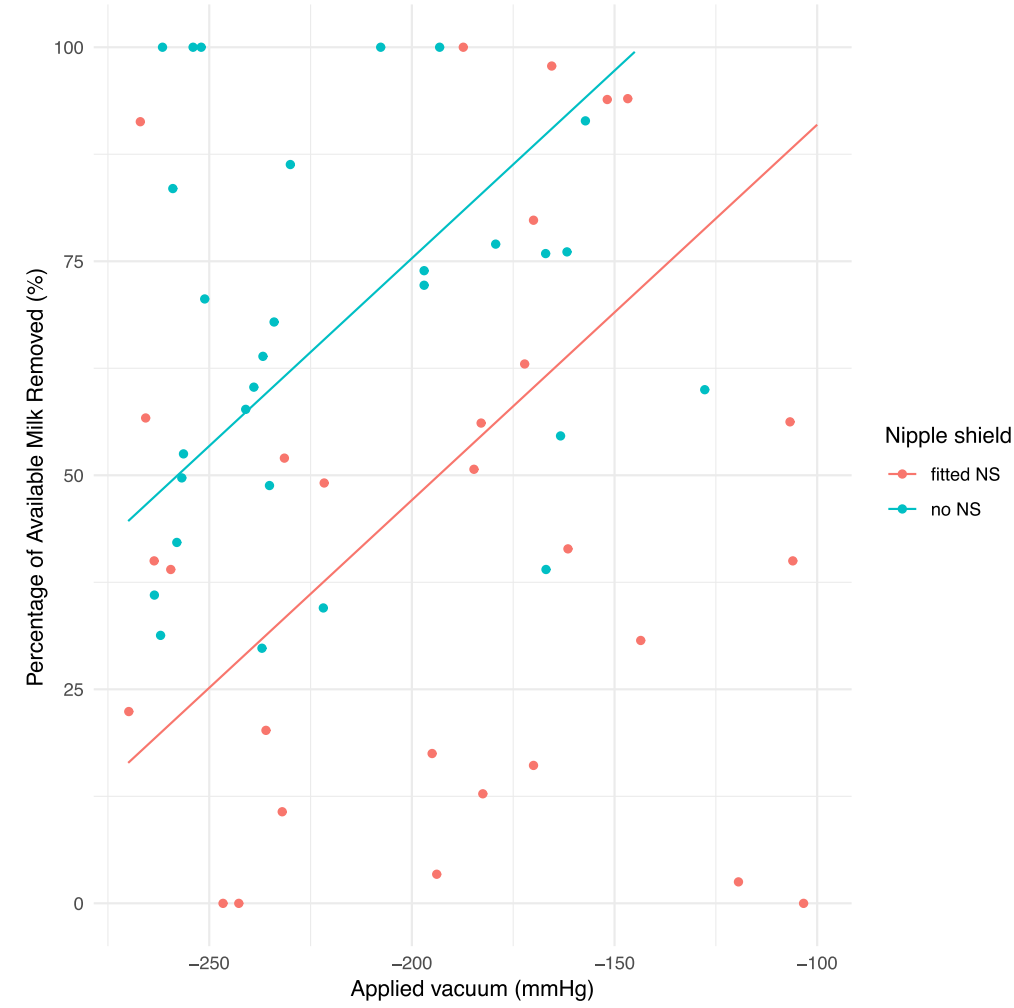

Fig. 1 Percentage of available milk removed (\%) and applied vacuum $(\mathrm{mmHg})$ with and without fitted NS

When considering all data, milk volume was associated with nipple shield use and degree of fullness of the breast. If a fitted nipple shield was used then the milk volume was $36.0 \mathrm{~mL}$ (10.3) lower than if no nipple shield was used $(p=0.002)$. A 0.1 unit increase in degree of fullness was associated with a $9.3 \mathrm{~mL}(2.7)$ increase in milk removed $(p=0.002)$. For the subset data, nipple shield use was not associated with milk volume $(p=$ 0.11 ), and a 0.1 unit increase in degree of fullness was associated with a $15.1 \mathrm{~mL}$ (5.3) increase in milk removed $(p=0.02)$.

Mothers in the PG scored higher and more variable pain scores than mothers in the CG during pumping, although more than half of PG scores indicated low pain levels (Table 3) [27].

Table 3 VAS and McGill median (IQR) scores for Pain and Control groups

\begin{tabular}{llll}
\hline & Pain group & Control group & $p$-value \\
\hline McGill no NS & $7(12)$ & $0(4)$ & 0.001 \\
McGill NS & $6(10)$ & $0(4)$ & 0.004 \\
VAS no NS & $3(3.5)$ & $0(0.5)$ & 0.01 \\
VAS NS & $1.5(1.3)$ & $0(0.7)$ & 0.01 \\
\hline
\end{tabular}

\section{Discussion}

Findings from this study suggest that use of a fitted nipple shield during pumping reduces effectiveness of milk removal. Also, both an increased degree of breast fullness, and increased strength of applied pumping vacuum are associated with a greater pumped milk volume.

The volume of milk removed from the breast during pumping is not an accurate indicator of pumping effectiveness as it does not account for the volume of milk in the breast prior to milk removal [19]. However, consistent with the percentage of available milk removed from the breast, the volume was also reduced, although this was not statistically significant when accounting for degree of breast fullness and applied vacuum. This is likely because the sample size of the subset group did not provide sufficient power to detect a statistically significant difference. Auerbach [16] reported reduced milk volume when pumping with a nipple shield, however her study assumed a constant application of vacuum with a nipple shield. The subjects included 25 mothers ranging from 6 weeks to 14 months of lactation. While differences in pumped milk volumes were solely attributed to nipple shield use, the wide span of lactation stages may have contributed several confounders such as reduced milk supply associated with complementary feeding of solids and/or formula or weaning [28]. Woolridge [12] demonstrated reduced milk volume transfer during 
breastfeeding with a rubber Mexican Hat nipple shield, but no significant difference when a thin latex nipple shield was used. The decreased milk transfer associated with Mexican Hat nipple shield use was attributed to observed altered sucking patterns including a faster suck rate and longer pauses, and possible failure of the milk ejection reflex. Neither study accounted for the starting degree of fullness of the breast. Our findings have shown that the degree of fullness influences the volume pumped regardless of nipple shield use.

Pumping with an appropriately sized nipple shield reduced the effectiveness of milk removal with approximately $25 \%$ less of the available milk removed than when pumping without a nipple shield (Table 2). The analysis included mothers that experienced nipple pain when breastfeeding and during the pumping session. While there were no differences in the effectiveness of milk removal between the mothers with pain and those without, ratings of pain were significantly higher than the control group (Table 3). The pain scores for the women experiencing pain were relatively low so it is unlikely that maternal nipple pain inhibited the milk ejection reflex and therefore milk removal [29, 30].

Greater proportions of the available milk were removed from the breast when applied pumping vacuum levels were stronger, regardless of whether a nipple shield was used (Fig. 1). This finding is consistent with previous pumping studies that have had the capacity to measure applied vacuum [31], contributing further evidence for the importance of applying the highest comfortable vacuum to enhance pumping effectiveness.

The results of this study also indicate that the degree of fullness or amount of milk available in the breast prior to pumping is related to the volume of milk removed such that the fuller the breast, the larger the volume of milk removed. Our findings concur with previous studies that have demonstrated an association between degree of breast fullness and pumped milk volume [32,33]. These findings highlight the importance of accounting for maternal factors such as $24 \mathrm{~h}$ milk production and degree of breast fullness when evaluating the effectiveness of milk removal from the breast, whether it be through pumping or breastfeeding.

\section{Study limitations}

The findings of this study must be viewed in light of the small sample of valid data, that was due to technical difficulties. While an association between nipple shield use and milk removal during pumping was observed in the subset of 11 participants with valid data, analysis based on the estimated required sample size of 30 would increase confidence in these results.

While this study was not designed to explore maternal nipple pain and its impact on milk removal during pumping, we recognise that pain is complex and may be impacted by perinatal mood disorders, previous and current pain experiences, and factors such as breast pump vacuum settings. Detailed studies of pain in breastfeeding mothers are needed to better understand its aetiology and impact on milk removal.

By the very nature of a mechanistic study, our results may inform our understanding of milk removal from the breast with a nipple shield in situ, but cannot be directly applied to the breastfeeding dyad. A clinical study of infant sucking dynamics during breastfeeding with and without a nipple shield is required to determine the impact of nipple shield use on milk removal.

\section{Conclusions}

Evidence from this mechanistic pumping study suggests that nipple shield use reduces milk removal from the breast. A detailed study of nipple shield use in breastfeeding dyads is required to determine the impact of nipple shields on infant sucking and milk removal from the breast. Breastfeeding mothers using a nipple shield should be monitored for adequate breast emptying and milk production.

\section{Abbreviations}

PG: Pain Group; CG: Control Group; NS: Nipple shield; VAS: Visual Analogue Scale; MPQ: McGill Pain Questionnaire; BPI: Brief Pain Questionnaire;

PAMR: Percentage of available milk removed; MCV: Maximum comfortable vacuum; SD: Standard deviation

\section{Acknowledgements}

We wish to acknowledge all the mothers for their participation.

\section{Authors' contributions}

VSC participated in study design, performed data collection, interpretation of the data and writing of the manuscript. SLP designed the study, assisted with data collection and interpretation and reviewed the manuscript. CTL assisted with data extraction and analysis. KM and AR provided statistical analysis. DTG designed the study, provided data interpretation and reviewed the manuscript. All authors reviewed and approved the manuscript prior submission.

\section{Authors' information}

Not applicable.

Funding

VSC received a scholarship from Science without Borders, Government of Brazil. The salaries of SP, CTL and DG are paid from an unrestricted research grant paid by Medela AG to The University of Western Australia. The funding bodies were not involved in the study design, collection, analysis and interpretation of data, writing of the manuscript and the decision to submit the manuscript for publication.

Availability of data and materials

All datasets generated or analysed during this study are available from the corresponding author on request.

Ethics approval and consent to participate

The study was approved and granted by Human Research Ethics Committee of the University of Western Australia (RA/4/1/4492). The participants provided written consent to participation.

Consent for publication

Not applicable. 


\section{Competing interests}

The authors declare that they have no competing interests. Medela AG currently provides an unrestricted research grant to The University of Western Australia, from which DTG, SLP and CTL receive salaries.

\section{Author details}

'School of Molecular Sciences, Faculty of Science, The University of Western Australia, M310, 35 Stirling Highway, Western Australia 6009 Crawley, Australia. ${ }^{2}$ Mathematics and Statistics, School of Engineering and Information Technology, Murdoch University, 90 South Street, Western Australia 6150 Murdoch, Australia. ${ }^{3}$ School of Population and Global Health, Faculty of Health and Medical Sciences, Population and Global Health, The University of Western Australia, M431, 35 Stirling Highway, Western Australia 6009 Crawley, Australia.

Received: 13 August 2019 Accepted: 19 August 2020

Published online: 07 September 2020

\section{References}

1. Schwartz K, D'Arcy HJ, Gillespie B, Bobo J, Longeway M, Foxman B. Factors associated with weaning in the first 3 months postpartum. J Fam Pract. 2002;51(5):439-44

2. Riordan J, Bibb D, Miller M, Rawlins T. Predicting breastfeeding duration using the LATCH breastfeeding assessment tool. J Hum Lact. 2001;17(1): 20-3.

3. Berens P, Eglash A, Malloy M, Steube AM. ABM Clinical Protocol \#26: Persistent Pain with Breastfeeding. Breastfeed Med. 2016;11:46-53.

4. Odom EC, Li R, Scanlon KS, Perrine CG, Grummer-Strawn L. Reasons for earlier than desired cessation of breastfeeding. Pediatrics. 2013;131(3): e726-32.

5. McClellan HL, Hepworth AR, Kent JC, Garbin CP, Williams TM, Hartmann PE, et al. Breastfeeding frequency, milk volume, and duration in mother-infant dyads with persistent nipple pain. Breastfeed Med. 2012;7:275-81.

6. Kent JC, Ashton E, Hardwick CM, Rowan MK, Chia ES, Fairclough KA, et al. Nipple Pain in Breastfeeding Mothers: Incidence, Causes and Treatments. Int J Environ Res Public Health. 2015;12(10):12247-63.

7. McClellan H, Geddes D, Kent J, Garbin C, Mitoulas L, Hartmann P. Infants of mothers with persistent nipple pain exert strong sucking vacuums. Acta Paediatr. 2008;97(9):1205-9.

8. McClellan HL, Hepworth AR, Garbin CP, Rowan MK, Deacon J, Hartmann PE, et al. Nipple pain during breastfeeding with or without visible trauma. J Hum Lact. 2012;28(4):511-21.

9. Chow S, Chow R, Popovic M, Lam H, Merrick J, Ventegodt S, et al. The Use of Nipple Shields: A Review. Front Public Health. 2015;3:236.

10. Chertok IR. Reexamination of ultra-thin nipple shield use, infant growth and maternal satisfaction. J Clin Nurs. 2009;18(21):2949-55.

11. Powers D, Tapia VB. Women's experiences using a nipple shield. J Hum Lact. 2004:20(3):327-34

12. Woolridge MW, Baum JD, Drewett RF. Effect of a traditional and of a new nipple shield on sucking patterns and milk flow. Early Hum Dev. 1980;4(4): 357-64

13. Brigham M. Mothers' reports of the outcome of nipple shield use. J Hum Lact. 1996;12(4):291-7.

14. Pincombe J, Baghurst P, Antoniou G, Peat B, Henderson A, Reddin E. Baby Friendly Hospital Initiative practices and breast feeding duration in a cohort of first-time mothers in Adelaide, Australia. Midwifery. 2008;24(1):55-61.

15. Eglash A, Ziemer AL, Chevalier A. Health professionals' attitudes and use of nipple shields for breastfeeding women. Breastfeed Med. 2010;5(4):147-51.

16. Auerbach KG. The effect of nipple shields on maternal milk volume. J Obstet Gynecol Neonatal Nurs. 1990;19(5):419-27.

17. Sakalidis VS, Kent JC, Garbin CP, Hepworth AR, Hartmann PE, Geddes DT Longitudinal changes in suck-swallow-breathe, oxygen saturation, and heart rate patterns in term breastfeeding infants. J Hum Lact. 2013;29(2):236-45.

18. Daly SE, Kent JC, Owens RA, Hartmann PE. Frequency and degree of milk removal and the short-term control of human milk synthesis. Exp Physiol. 1996;81(5):861-75.

19. Daly SE, Di Rosso A, Owens RA, Hartmann PE. Degree of breast emptying explains changes in the fat content, but not fatty acid composition, of human milk. Exp Physiol. 1993;78(6):741-55.

20. Huskisson EC. Measurement of pain. Lancet. 1974;2(7889):1127-31.
21. Bijur PE, Silver W, Gallagher EJ. Reliability of the visual analog scale for measurement of acute pain. Acad Emerg Med. 2001:8(12):1153-7.

22. Melzack R. The McGill Pain Questionnaire: major properties and scoring methods. Pain. 1975;1(3):277-99.

23. Arthur PG, Hartmann PE, Smith M. Measurement of the milk intake of breast-fed infants. J Pediatr Gastroenterol Nutr. 1987;6(5):758-63.

24. Casey CE, Hambidge KM, Neville MC. Studies in human lactation: zinc, copper, manganese and chromium in human milk in the first month of lactation. Am J Clin Nutr. 1985;41(6):1193-200.

25. Daly SE, Owens RA, Hartmann PE. The short-term synthesis and infantregulated removal of milk in lactating women. Exp Physiol. 1993;78(2):20920

26. Kent JC, Ramsay DT, Doherty D, Larsson M, Hartmann PE. Response of breasts to different stimulation patterns of an electric breast pump. J Hum Lact. 2003;19(2):179. :- 86; quiz 87 - 8, 218.

27. Boonstra AM, Schiphorst Preuper HR, Balk GA, Stewart RE. Cut-off points for mild, moderate, and severe pain on the visual analogue scale for pain in patients with chronic musculoskeletal pain. Pain. 2014;155(12):2545-50.

28. Kent JC, Mitoulas L, Cox DB, Owens RA, Hartmann PE. Breast volume and milk production during extended lactation in women. Exp Physiol. 1999; 84(2):435-47.

29. McNeilly AS, Robinson IC, Houston MJ, Howie PW. Release of oxytocin and prolactin in response to suckling. Br Med J (Clin Res Ed). 1983;286(6361): 257-9.

30. Prime DKG, Hartmann D, Oxytocin P. Milk ejection and maternal-infant wellbeing. In: Hale TWH, P.E., editor. Textbook of Human Lactation. Vol. 1. Texas: Hale Publishing; 2007. pp. 141-58.

31. Mitoulas LR, Lai CT, Gurrin LC, Larsson M, Hartmann PE. Effect of vacuum profile on breast milk expression using an electric breast pump. J Hum Lact. 2002;18(4):353-60.

32. Prime DK, Geddes DT, Hepworth AR, Trengove NJ, Hartmann PE. Comparison of the patterns of milk ejection during repeated breast expression sessions in women. Breastfeed Med. 2011:6(4):183-90.

33. Prime DK, Kent JC, Hepworth AR, Trengove NJ, Hartmann PE. Dynamics of milk removal during simultaneous breast expression in women. Breastfeed Med. 2012;7(2):100-6.

\section{Publisher's Note}

Springer Nature remains neutral with regard to jurisdictional claims in published maps and institutional affiliations.
Ready to submit your research? Choose BMC and benefit from:

- fast, convenient online submission

- thorough peer review by experienced researchers in your field

- rapid publication on acceptance

- support for research data, including large and complex data types

- gold Open Access which fosters wider collaboration and increased citations

- maximum visibility for your research: over $100 \mathrm{M}$ website views per year

At $\mathrm{BMC}$, research is always in progress.

Learn more biomedcentral.com/submissions 